\title{
Phylogeny, species delimitation and convergence in the South American bothriurid scorpion genus Brachistosternus Pocock 1893: Integrating morphology, nuclear and mitochondrial DNA
}

\author{
Andrés A. Ojanguren-Affilastro ${ }^{1 *}$, Camilo I. Mattoni ${ }^{2}$, José A. Ochoa ${ }^{3}$, Martín J. Ramírez ${ }^{1}$, F. \\ Sara Ceccarelli ${ }^{1}$, and Lorenzo Prendini ${ }^{4}$
}

\begin{abstract}
${ }^{1}$ Museo Argentino de Ciencias Naturales “Bernardino Rivadavia," Avenida Ángel Gallardo 470, CP: 1405DJR, CABA, Buenos Aires, Argentina (ojanguren@macn.gov.ar and andres.ojanguren@gmail.com; ramirez@macn.gov.ar; saracecca@hotmail.com)

${ }^{2}$ Laboratorio de Biología Reproductiva y Evolución, Instituto de Diversidad y Ecología Animal (IDEA, CONICET-UNC), Facultad de Ciencias Exactas, Físicas y Naturales, Universidad

Nacional de Córdoba, Av. Vélez Sársfield 299, 5000, Córdoba, Argentina (cmattoni@efn.uncor.edu)

${ }^{3}$ Frankfurt Zoological Society - Peru, Residencial Huancaro, Los Cipreses H-21, Santiago, Cusco, Perú (jaochoac2000@yahoo.com)

${ }^{4}$ Scorpion Systematics Research Group, Division of Invertebrate Zoology, American Museum of Natural History, Central Park West at $79^{\text {th }}$ Street, New York, NY 10024-5192, U.S.A. (lorenzo@amnh.org)
\end{abstract}

* Corresponding author email: ojanguren@macn.gov.ar and andres.ojanguren@gmail.com

\begin{abstract}
A phylogenetic analysis of the scorpion genus Brachistosternus Pocock, 1893 (Bothriuridae Simon, 1880) is presented, based on a dataset including 41 of the 43 described species and five outgroups, 116 morphological characters and more than 4150 base-pairs of DNA sequence from the nuclear 18S rDNA and 28S rDNA gene loci, and the mitochondrial 12S rDNA, 16S rDNA, and Cytochrome c Oxidase Subunit I gene loci. Analyses conducted using parsimony, Maximum Likelihood and Bayesian Inference were largely congruent with high support for most clades. The results confirmed the monophyly of Brachistosternus, the nominal subgenus, and subgenus Ministernus Francke, 1985, as in previous analyses based only on morphology, but differed in several other respects. Species from the plains of the Atacama Desert diverged basally whereas the high altitude Andean species radiated from a more derived ancestor, presumably as a consequence of Andean uplift and associated changes in climate. Species limits were assessed among species that contain intraspecific variation (e.g., different morphs), are difficult to separate morphologically, and/or exhibit widespread or disjunct
\end{abstract}


distributions. The extent of convergence in morphological adaptation to life on sandy substrata (psammophily) and the complexity of the male genitalia, or hemispermatophores, were investigated. Psammophily evolved on at least four independent occasions. The lobe regions of the hemispermatophore increased in complexity on three independent occasions, and decreased in complexity on another three independent occasions.

Keywords: Scorpiones; systematics; Brachistosternus; Phylogeny; South-America.

\section{Introduction}

The resolution of species relationships by phylogenetic reconstruction is fundamental to the study of evolution, yet data and methods were fiercely debated in the past (Wagner, 2001). Whereas much energy was expended by some in attempting to determine the most reliable sources of data, others emphasized the benefits of combining diverse sources of data, which may yield new hypotheses that are not otherwise recovered (e.g., Baker et al., 1998; Farias et al., 2000; Lopardo et al., 2011). This integrative approach is increasingly used, in some cases with all data sources leading to similar results (e.g., Prendini et al., 2005; Crews \& Hedin, 2006; Agnarsson et al., 2007; Talal et al., in press) and, in others, revealing discordances which point to interesting underlying evolutionary mechanisms, such as the convergence of traits, often but not exclusively resulting from directional selection (e.g., Quicke \& Belshaw, 1999; Mott \& Vieites, 2009; Hedin \& Thomas, 2010). The combination of data sources is especially advantageous in studies at the species level and is essential to satisfactorily determine the limits of species in complex and diverse taxa, common among arthropods.

The scorpion genus Brachistosternus Pocock 1893 currently includes 43 described species (Ojanguren-Affilastro \& Pizarro-Araya, 2014), and is the most diverse genus of the family Bothriuridae Simon, 1880 (Kovařík \& Ojanguren-Affilastro, 2013). Brachistosternus occurs in most arid to semi-arid habitats of southern and western South America from extreme southern Patagonia to Ecuador, from the Pacific to the Atlantic, and from sea level to over 4500 $\mathrm{m}$ in the Andes. Brachistosternus species are medium-sized scorpions that are usually very abundant, and in most cases the dominant scorpion taxa in areas where they occur (Agusto et al., 2006; Nime et al., 2013, 2014). All species of the genus are fossorial, constructing simple burrows usually in bare, dry substrata, the upper layers of which are loose (semi-consolidated). Although most species of the genus thrive on soils rich in loam, silt or clay, many inhabit softer, sandy substrata including stable or shifting sand dunes, dry river beds, and alluvial fans. The species of Brachistosternus may be defined as semi-psammophilous to ultrapsammophilous (Prendini, 2001) based on the presence of ecomorphological adaptations for burrowing in loose, dry (semi-consolidated to unconsolidated) substrata of varying hardness and texture, including dorsoventrally compressed basitarsi, laterally compressed telotarsi, combs of elongated 
macrosetae on the pro- and especially retrolateral margins of the basitarsi and the dorsal margins of the telotarsi, and setiform pro- and retroventral setae on the telotarsi (Prendini, 2000).

Besides the specialized psammophilous adaptations of some species, many species of Brachistosternus possess the most complex hemispermatophores among scorpions in which these structures have been studied (Ojanguren-Affilastro \& Ramirez, 2009). The hemispermatophores are the two internal halves of the spermatophore, the secondary reproductive structure of male scorpions, which fuse just prior to extrusion from the male genital aperture, attachment to the substrate and subsequent partial introduction into the female genital aperture during mating. The hemispermatophores of Brachistosternus exhibit diverse spines, lobes, and other structures which, in some cases, are asymmetrical (e.g., the cylindrical apophysis).

Brachistosternus is among the best known scorpion genera in South America, from taxonomic and geographical perspectives, and a suitable model for fine-scale analysis of morphological evolution. The taxonomy of Brachistosternus has been extensively revised in the past decade (Ojanguren-Affilastro \& Roig-Alsina, 2001; Ochoa \& Acosta, 2002; OjangurenAffilastro, 2002a, b, c, 2003a, b, 2004a; Ochoa \& Ojanguren-Affilastro, 2007; OjangurenAffilastro et al., 2007; Ojanguren-Affilastro \& Ramírez, 2009; Ojanguren-Affilastro \& PizarroAraya 2014), more than doubling the number of described species listed by Lowe \& Fet (2000). The marked increase in known diversity is attributed to intensive sampling across the geographical distribution of the genus, aided by ultraviolet (UV) light detection, and the application of modern concepts of species. In spite of extensive work on the taxonomy of Brachistosternus, species diagnosis remains challenging as most species lack unique diagnostic characters, and must be separated using a limited combination of characters. Although minimal in most Andean species, intraspecific variation may be extensive among the lowland plains species with widespread distributions, resulting in taxonomic challenges that cannot be resolved with morphology alone.

Recent phylogenetic analyses of family Bothriuridae (Prendini, 2000, 2003; Mattoni \& Prendini, 2007), based on exemplar species, unambiguously recovered the monophyly of Brachistosternus, but did not assess its internal relationships. Ojanguren-Affilastro \& Ramírez (2009) performed the first phylogenetic analysis of species-level relationships in the genus, based on morphological data, on the basis of which subgenus Ministernus Francke 1985 was upheld and subgenus Leptosternus Maury, 1973 synonymized with Brachistosternus. Two major, monophyletic groups of species, i.e., an Andean group and a plains group, were identified in the nominotypical subgenus. The low support values for the groups recovered (Ojanguren-Affilastro \& Ramírez, 2009) suggested that the characters on which it was based, were less informative for phylogenetic reconstruction than for species delimitation, or suffered from concerted convergence that biased the results. The availability of other sources of data 
(i.e., DNA sequences) provides an opportunity to produce a more robust phylogeny on which to explore the evolution of morphological characters.

The present contribution provides the first phylogenetic analysis of Brachistosternus based on molecular and morphological data. More than 4150 base-pairs (bp) of DNA sequence from two nuclear gene loci, 18S rDNA (18S) and 28S rDNA (28S), and three mitochondrial gene loci, 12S rDNA (12S), 16S rDNA (16S), and Cytochome c Oxidase Subunit I (COI), were combined with 116 morphological characters from Ojanguren-Affilastro \& Ramírez (2009) for a dataset including 41 of the 43 described species of Brachistosternus and five outgroups, including four other bothriurid genera. Analyses were conducted using parsimony, Maximum Likelihood and Bayesian Inference. The aims were to resolve the internal relationships among the species of Brachistosternus and test the monophyly and validity of its subgenera and species groups; to assess the limits of species that contain intraspecific variation (e.g., different morphs), are difficult to separate morphologically, and/or exhibit widespread or disjunct distributions; and to investigate the extent of convergence in morphological adaptations to life on sandy substrata (psammophily) and the complexity of the male hemispermatophore.

\section{Materials and Methods}

\subsection{Taxon Sample}

Exemplar species of four bothriurid genera were selected as outgroup taxa based on recent phylogenetic analyses of family Bothriuridae (Prendini, 2000, 2003; Mattoni \& Prendini, 2007): Thestylus aurantiurus Yamaguti \& Pinto-da-Rocha, 2003; Bothriurus flavidus Kraepelin, 1911; Cercophonius sulcatus Kraepelin, 1908; and Urophonius brachycentrus (Thorell, 1876). The tree was rooted on Scorpio fuscus (Ehrenberg, 1829), an exemplar species of family Scorpionidae Latreille 1802, representing superfamily Scorpionoidea Latreille 1802, the putative sister-group of Bothriuridae (Prendini, 2000).

Forty-one of the 43 nominal species of Brachistosternus were included as ingroup taxa. Brachistosternus castroi Mello-Leitão, 1941 and Brachistosternus holmbergi Carbonell, 1923 were not included because they are of dubious validity (Ojanguren-Affilastro \& Ramírez, 2009; Kovařík \& Ojanguren-Affilastro, 2013). Samples of Brachistosternus mattonii OjangurenAffilastro, 2005, could not be obtained for DNA isolation. Eighteen species were represented by a single specimen, whereas 22 species were represented by two or more specimens (seven species by two specimens, five by three, two by four, three by five, three by seven, and two by eight), each usually from a different locality (a proxy for different populations), in order to test species limits. In total, 107 terminals belonging to 40 species were included. 
Species with known intraspecific variation (e.g., different morphs, defined as a local variety of a species, morphologically distinguishable from other populations of the species) were represented by at least one specimen of each, and species with widespread distributions, by specimens from central and peripheral points of the known distribution, to the extent possible.

Brachistosternus angustimanus Ojanguren-Affilastro \& Roig-Alsina, 2001 occurs in a wide area of central Patagonia. North-western populations exhibit minor morphological differences from typical south-eastern populations (Ojanguren-Affilastro \& Roig-Alsina, 2001). Five different populations were compared to test whether distant populations of this species are conspecific.

The typical form of Brachistosternus cekalovici Ojanguren-Affilastro, 2005 inhabits shrub steppes with a clay substratum. However, some populations, inhabiting coastal dunes that are usually isolated from each other by several kilometres of shrub steppe, exhibit minor morphological differences from one another and from the typical form (Ojanguren-Affilastro $e t$ al., 2007). Five specimens from different populations of B. cekalovici were compared to test whether they are conspecific.

Brachistosternus ehrenbergii (Gervais, 1841) occupies a wide area from northern Chile to central Peru, and exhibits some intraspecific differences among populations (Ochoa \& Ojanguren-Affilastro, 2007). Putative records from Ecuador (Brito \& Borges, 2015) are erroneous and correspond to B. pegnai. Seven specimens from across the known distribution were compared to test whether these populations are conspecific.

Brachistosternus ferrugineus (Thorell, 1876) occupies a large area, including central and northern Argentina, Bolivia, Paraguay and, probably, southern Brazil. Despite its broad distribution, morphological differences between distant populations of $B$. ferrugineus are minor, and cytogenetic studies revealed no differences (Rodrígez-Gil et al., 2009). The identity of Brachistosternus simoneae Lourenço, 2000 remains questionable. Diagnostic characters provided in the original description (Lourenço, 2000) overlap with those of B. ferrugineus (Kovařík \& Ojanguren-Affilastro, 2013) and examination of specimens of the putative species failed to identify consistent differences with $B$. ferrugineus. Five specimens from distantly separated populations of $B$. ferrugineus were compared, together with one specimen identified as $B$. simoneae because it was collected close to the type locality of the latter, to test whether distant populations of $B$. ferrugineus are conspecific with one another, and with B. simoneae.

Brachistosternus intermedius Lönnberg, 1902 occurs at very high altitudes from northern Argentina to central Bolivia, where it is replaced by Brachistoternus titicaca Ochoa \& Acosta, 2002, a morphologically similar species which occupies a similar habitat and niche (Ochoa \& Acosta, 2002; Kovařík \& Ojanguren-Affilastro, 2013). Seven specimens of $B$. intermedius from across the distribution were compared with one another, and with B. titicaca, to test whether they are conspecific. Brachistosternus piacentinii Ojanguren-Affilastro, 2003, Brachistosternus kovariki Ojanguren-Affilastro, 2003, and Brachistosternus zambrunoi 
Ojanguren-Affilastro, 2002 were also included in these analyses, because they grouped among populations of $B$. intermedius in some of the phylogenetic analyses.

Brachistosternus kamanchaca Ojanguren-Affilastro et al., 2007 is distributed throughout most of the coastal transitional desert of Chile. Different populations exhibit some morphological variation (Ojanguren-Affilastro et al., 2007). Four specimens from different populations, as well as the closely related species, Brachistosternus barrigai OjangurenAffilastro, 2014, were compared to test whether they are conspecific.

Brachistosternus montanus Roig-Alsina, 1977 occurs at high altitudes in central Argentina. Northern populations of this species differ morphologically from typical southern populations and were previously suggested to be a different species (Ojanguren-Affilastro, 2003b). Seven specimens from different populations across the distribution were compared to test whether they are conspecific.

Brachistosternus multidentatus Maury, 1984 is known from only two, apparently disjunct populations, ca. $1000 \mathrm{~km}$ apart, and without any known intermediate populations. One population inhabits dunes in central-western Argentina, and the other inhabits dunes on the Atlantic coast of central-eastern Argentina (Maury, 1984; Ojanguren-Affilastro, 2005). These populations do not exhibit conspicuous morphological differences. However, due to their apparent isolation, specimens of each were included to test whether they are conspecific.

Brachistosternus paulae Ojanguren-Affilastro, 2003 inhabits a wide area of southern Patagonia, from the coast to the eastern slopes of the austral Andes. Three specimens from geographically distant populations were compared to test whether they are conspecific.

Brachistosternus pentheri Mello-Leitão, 1931 inhabits a vast area of central-western Argentina. Northern populations differ from typical southern populations (Rodríguez Gil et al., 2009) morphologically as well as in chromosome number (Roig-Alsina \& Maury 1984). Eight specimens from geographically distant populations were compared to test whether they are conspecific.

Brachistosternus roigalsinai Ojanguren-Affilastro, 2002 is widely distributed in the coastal transitional desert of north-central Chile (Ojanguren-Affilastro, 2007). Different populations exhibit some morphological variation (Ojanguren-Affilastro, 2002a). Eight specimens from different populations, as well as the closely related species, Brachistosternus paposo Ojanguren-Affilastro \& Pizarro, 2014, were compared to test whether they are conspecific.

Brachistosternus weijenberghii (Thorell, 1876) inhabits an area approximately $1000 \mathrm{~km}$ long and $150 \mathrm{~km}$ wide at intermediate altitudes of the central and northern Andes of Argentina. Two slightly different morphs occur at the northern and southern extremes of the distribution, the southern of which was recognized as a different species, Brachistosternus borellii Kraepelin, 1911 (Roig-Alsina \& Maury, 1981), until it was synonymized with B. weijenberghii (Ojanguren-Affilastro, 2002b). Specimens from two northern populations and two southern 
populations were compared to test whether they are conspecific, and to evaluate the validity of the synonymy.

\subsection{Material Examined}

Most specimens were hand collected by the authors at night using portable UV lamps, comprising mercury vapor tubes attached to a chromium reflector, and powered by a $12 \mathrm{~V}, 7$ amp/hour battery, or Maglite flashlights modified with UV light-emitting diode (LED) attachments. Some specimens were collected during the day by excavating burrows. Most specimens were preserved in $80 \%$ ethanol for morphological study. One or two juvenile specimens and, when available, an adult conspecific from the same collection event, were preserved in $95 \%$ ethanol for DNA isolation, following standard procedures (Prendini et al., 2002, 2003). Tissue samples from which DNA was extracted are stored (in the vapor phase of liquid nitrogen at $-150^{\circ} \mathrm{C}$ ) in the Ambrose Monell Collection for Molecular and Microbial Research (AMCC) at the American Museum of Natural History (AMNH), New York (Appendix A). Additional material, deposited in the Argentine National Arachnological Collection, Museo Argentino de Ciencias Naturales 'Bernardino Rivadavia', Buenos Aires, was examined for the morphological character matrix (Appendix B).

\subsection{Morphological Data}

The morphological character matrix of Ojanguren-Affilastro \& Ramírez (2009), comprising 116 characters, was adopted and modified. Five outgroup taxa from the previous analysis were omitted, while two (C. sulcatus and S. fuscus) were added. The states of some characters were adjusted to accommodate these omissions and additions to the taxon sample. For example, the number of states in character 34 was reduced from 11 to 8 (Appendices C, D). Hemispermatophores were dissected from surrounding tissues and observed in $80 \%$ ethanol.

\subsection{DNA Sequencing}

Five gene loci were selected to reconstruct the phylogeny of Brachistosternus because they evolve at different rates and provide phylogenetic resolution at different, overlapping taxonomic levels (Prendini et al., 2003, 2005; González-Santillán \& Prendini, 2014; Santibáñez-Lopez et al., 2014). Approximately 513 base-pairs (bp) of the D3 region of the large-subunit ribosomal RNA (28S rDNA) gene, and ca. 1,761 bp of the small-subunit ribosomal RNA (18S rDNA) gene were sequenced from the nuclear genome, as well as ca. $485 \mathrm{bp}$ of the large-subunit 
ribosomal RNA (16S rDNA) gene, ca. 335 bp of the small-subunit ribosomal RNA (12S rDNA) gene and 1,078 bp of the Cytochrome c Oxidase Subunit I (COI) gene, incorporating the DNA barcoding fragment (Hebert et al., 2003), from the mitochondrial genome.

Genomic DNA was extracted from muscle tissue taken from the leg or pedipalp of each specimen using the Qiagen DNeasy Blood and Tissue Kit. DNA was amplified using PureTaqReady-To-Go PCR Beads (GE Healthcare), $1 \mu 1$ of each primer (Appendix E), 2-4 $\mu 1$ of DNA template, and 19-21 $\mu \mathrm{l}$ of molecular grade water for a total reaction volume of $25 \mu 1$. The following adjuvants were added for samples that proved difficult to amplify: 2-4 $\mu 1$ of Magnesium Chloride, 0.5-1 $\mu 1$ of Fisher BioReagents Bovine Serum Albumine (BSA), and/or $0.5-1 \mu l$ of $5 \%$ Dimethyl Sulfoxide (DMSO), adjusting the total reaction volume to $25 \mu 1$ with molecular grade water. Alternatively, illustra Hot Start Mix RTG beads (GE Healthcare) were used without adjuvants. All amplifications were performed in an Eppendorff Mastercycler thermocycler using the following thermal profile: $94^{\circ} \mathrm{C}$ for $3-5 \mathrm{~min} ; 35-40$ cycles of $94-95^{\circ} \mathrm{C}$ for $15-30 \mathrm{~s}, 42-52^{\circ} \mathrm{C}$ for $15-30 \mathrm{~s}, 72^{\circ} \mathrm{C}$ for $15-30 \mathrm{~s} ; 72^{\circ} \mathrm{C}$ for $10 \mathrm{~min}$. PCR products were verified on a $1 \%$ agarose-TBE electrophoresis gel stained with SYBR Safe (Invitrogen). Amplified products were purified using an Ampure Magnetic Beads Purification System (Agentcourt) and re-suspended in $40 \mu \mathrm{l}$ of molecular grade water using a Biomek NX robot (Beckman-Coulter).

Amplification products were sequenced in both directions. Two optimized protocols were used, depending on the length of the fragment. Whereas each $8 \mu 1$ sequencing reaction mixture included $0.3 \mu \mathrm{l}$ of Big Dye, $1 \mu \mathrm{l}$ of Big Dye Terminating buffer, $1 \mu 1$ of $3.2 \mathrm{pm}$ primer, $5 \mu \mathrm{l}$ of gene amplification product and $0.7 \mu \mathrm{l}$ of molecular grade water for fragments less than $500 \mathrm{bp}$, the $8 \mu \mathrm{l}$ mixture included $0.5 \mu \mathrm{l}$ of Big Dye and $0.5 \mu \mathrm{l}$ of molecular grade water for fragments greater than 500 bp. Samples were sequenced in an Eppendorff Mastercycler thermocycler using 35 cycles of the following thermal profile: $96^{\circ} \mathrm{C}$ for $15 \mathrm{~s}, 50^{\circ} \mathrm{C}$ for $15 \mathrm{~s}$, $60^{\circ} \mathrm{C}$ for $4 \mathrm{~min}$. Cycle-sequenced products were cleaned using CleanSeq magnetic beads on the Biomex NX robot. Products were re-suspended in EDTA and $33 \mu l$ were sequenced on an Applied Biosystems, Inc. (ABI) 3730xl automated capillary DNA sequencer.

The accuracy of sequences was verified by independently amplifying and sequencing the complementary strands of all fragments. Primer sequences were removed and complementary strands of DNA assembled into consensus sequences, edited, and checked for quality using Sequencher 5.0 (Gene Codes Co.). If complementary strands disagreed (besides minor mismatches), the sample was reamplified and sequenced to resolve discrepancies.

In total, 570 sequences were generated from 114 samples for the study (Appendix A; Table 1). All except one ingroup COI sequence (Brachistosternus alienus 2256) of $376 \mathrm{bp}$, were complete. The 12S fragment varied from 330-339 bp: 330 bp (1 outgroup), 332 bp (7 ingroups), 333 bp (33 ingroups), 334 bp (3 outgroups, 28 ingroups), 335 bp (32 ingroups), 336 bp (2 
ingroups), $337 \mathrm{bp}$ (1 outgroup, 6 ingroups), $339 \mathrm{bp}$ (1 ingroup). The $16 \mathrm{~S}$ fragment varied from 481-486 bp: 481 bp (2 outgroups, 9 ingroups), 482 bp ( 2 outgroups, 47 ingroups), 483 bp (1 outgroup, 29 ingroups), 484 bp (22 ingroups), 485 bp (1 ingroup), or 486 bp ( 1 ingroup). Length variation was minimal in 28S: 513 bp (3 outgroups, all ingroups), 514 bp (1 outgroup), or 517 bp (1 outgroup). All complete COI sequences were 1078 bp and all 18S sequences were 1761 bp.

\subsection{Multiple Sequence Alignment and Phylogenetic Reconstruction}

Edited sequences of the three gene loci with length variation (28S, 12S and $16 \mathrm{~S})$ were aligned prior to phylogenetic analysis. Alignment of the $28 \mathrm{~S}$ sequences, conducted in the online version of MAFFT v.7 (Katoh and Standley, 2013), by applying the "Auto" strategy and a gap opening penalty of 1.53 , was trivial. Alignment of the $12 \mathrm{~S}$ and $16 \mathrm{~S}$ ribosomal sequences, which contained regions of ambiguous alignment representing hypervariable regions (HVRs) unlikely to evolve on a per-site nucleotide substitution basis, was conducted in the online version of MxScarna (http://mxscarna.ncrna.org/), by applying a secondary structure model with a stem candidate length of 2 and a threshold of base pairing probability of 0.01 . Regions of the $12 \mathrm{~S}$ and $16 \mathrm{~S}$ alignments comprising more than two continuous gaps in at least $5 \%$ of the taxa were excised and re-coded as multi-nucleotide character states in a presence/absence matrix per haplotype (Appendix F), following Lutzoni et al. (2000). Alignment was not required for the COI sequences, in which codon positions were determined using Bioedit v. 7.2 .5 (Hall, 1999).

Nucleotide composition homogeneity tests were conducted separately on the alignments of each locus (and codon position for COI) using Tree-Puzzle v. 5.2 (Schmidt et al., 2002) to verify, based on a chi-squared test, whether all partitions were appropriate for phylogenetic reconstruction (Rosenberg \& Kumar, 2003). Nucleotide characteristics of each locus in Brachistosternus were calculated using DnaSP v. 5.10.1 (Librado \& Rozas, 2009).

Phylogenies were reconstructed using parsimony, Maximum Likelihood (ML) and Bayesian Inference (BI), on the morphological data (parsimony), the molecular data (parsimony, $\mathrm{ML}$ and $\mathrm{BI}$ ), and the combined dataset (parsimony, ML and $\mathrm{BI}$ ). Parsimony analyses were conducted with TNT v. 1.1 (Goloboff et al., 2008a) under equal weights and implied weights, varying the constant of concavity, $k$, between 5 and 100 , to select a range with stable results that maximized congruence between the morphological and molecular data, as well as with the tree obtained by BI. The tree search was set to hit the minimum cost 100 times using default parameters of the "new technology search" (Goloboff, 2002). Nodal support was assessed with the bootstrap, calculated using a heuristic search, set to hit the minimum cost three times using default parameters of the "new technology search" for each of the 1000 preudoreplicates, the consensus of each pseudoreplicate calculated by collapsing with tree-bisection-reconnection. 
ML and BI analyses were conducted via the CIPRES Science Gateway V. 3.3 (Miller et al., 2010) on four different data matrices: DNA excluding re-coded HVRs, henceforth 'DNA'; DNA including re-coded HVRs, henceforth 'DNA+HVRs'; morphology and DNA excluding re-coded HVRs, henceforth 'mor+DNA'; morphology and DNA including re-coded HVRs, henceforth 'mor+DNA+HVRs'. The best partitioning scheme and substitution model for each DNA partition was chosen with the Bayesian Information Criterion (Schwarz, 1978), deemed less generalist and more realistic with adequate sample sizes than the Akaike Information Criterion (Akaike, 1973; see Burnham \& Anderson, 2004) using the "greedy" search strategy in PartitionFinder v. 1.1.1 (Lanfear et al. , 2014).

ML analyses were conducted with RAxML v. 8.0.24 (Stamatakis, 2014), using the rapid bootstrapping algorithm and GTRGAMMA substitution model for DNA, and the MULTIGAMMA model for mor+DNA+HVRs, as this has been shown to provide accurate results (Stamatakis et al., 2007) when applied to a mixed model as determined by PartitionFinder.

BI was conducted using Markov Chain Monte Carlo (MCMC) simulations in MrBayes v. 3.2.1 (Ronquist et al. 2012) with two parallel runs of four simultaneous chains for 10 million generations, sampling every 1000 generations. The partitioning scheme applied and the nucleotide substitution models set as priors for each partition are listed in Appendix G. The $M k$ model for morphology (Lewis, 2001), with a variable ascertainment bias, a dirichlet prior assuming equal frequencies for all states, and a gamma rate prior was applied to the morphological characters. Due to differences among the DNA fragments, the substitution rates were set to vary, and the character state frequencies and gamma shape parameters unlinked across partitions. The first two million generations were discarded as burn-in on generating a consensus tree, based on the likelihoods reaching stationarity, and whether the effective sample size of all parameters was $>200$, using Tracer v.1.5 (Rambaut \& Drummond, 2007). Nodal support was assessed with 1000 non-parametric bootstrap replicates (ML; Felsenstein, 1985) and posterior probabilities (BI).

\subsection{Species Delimitation Methods}

The limits of the abovementioned twelve species of Brachistosternus were tested with a General Mixed Yule-Coalescent (GMYC) model (Pons et al., 2006), implemented in the R v. 3.0.2 (R core team, 2013) package "splits" v. 1.0-19 (Ezard et al., 2009). Both single and multiple rate GMYC models were implemented for the phylogeny obtained from MrBayes (DNA+HVRs), converted to an ultrametric tree using the penalized likelihood (PL) method (Sanderson, 2002) in r8s v. 1.8 (Sanderson, 2003) with the truncated Newton (TN) algorithm, as recommended by the developer, and setting the rates to gamma (Appendix H). As node ages 
were not required, the age was set relative to one taxon (in this case, Brachistosternus andinus Chamberlin, 1916). In addition to the GMYC model, a Bayesian implementation thereof was applied, using the R package "bGMYC" v. 1.0.2 (Reid \& Carstens, 2012), to a random sample of 100 of the last 500 trees from each of the two Bayesian runs (again converted to ultrametric trees using the PL method with the TN algorithm in r8s), setting the MCMC simulation at 50,000 generations with a burn-in of 40,000, sampling every hundredth generation. After initial tests with varying Yule and coalescent rate change parameters on a single tree, the upper and lower bounds of the Yule and coalescent rate change parameters were set, respectively, to 1 and 0.05 , and the upper bound of the threshold parameter to 103 (number of tips in the trees, for ingroup taxa only).

Whereas several recent studies praised the GMYC method as a solid method for species delimitation (e.g., Monaghan et al., 2009; Brewer et al., 2012; Ceccarelli et al., 2012) others criticized its efficacy (e.g., Carstens et al., 2013; Miralles \& Vences, 2013). Bayes Factor species delimitation (BFD; Grummer et al., 2014) was therefore also applied as a likelihoodbased hypothesis testing method for identification of individuals whose assignment to particular species was uncertain. An advantage is that BFD can detect "misplaced" individuals (due to topological errors) in addition to "lumped" or "split" individuals. BFD also takes incongruence between gene trees and species trees (Degnan \& Rosenberg, 2009) into account by applying multispecies coalescence analysis.

The limits of the twelve species were independently tested using the coalescent species tree algorithm *BEAST (Heled \& Drummond, 2010) in BEAST v. 1.8.0 (Drummond et al., 2012), while estimating the marginal likelihood (MLE) by path-sampling (PS; Lartillot \& Philippe, 2006) and stepping-stone sampling (SS; Xie et al., 2011). PS and SS can be used as a means of comparing the MLEs of the runs, also taking into account the importance of proper priors (Baele et al., 2012, 2013), such that when the same informative priors are set for the parameters of the runs, the changes in MLE between runs are due to the alternative "species" groups set as inputs. Each coalescent species tree analysis was conducted on the complete dataset and again with some of the partitions (18S, 28S, or both) removed, when these contained no variable sites among the terminal taxa in particular analyses.

Molecular clock rates were estimated, nucleotide substitution models simplified to HKY (Hasegawa et al., 1985) for all partitions to avoid over-parametrization, the prior for the species tree set as a Birth-Death process, and the piecewise linear and constant root used for the population size model. Lognormal priors with initial values of 1 , mean values of 0.01 and 1 standard deviation were set as priors for mean uncorrelated lognormal clock, population hyperparameter and Yule process birth rate parameters. The priors set for the remaining parameters were informative and constant for all runs. Markov-Chain Monte Carlo chains were set to run for 20 million generations, sampling every 1000 generations. Additionally, the MLE chain was set to run for 5 million generations with 200 path steps. Each postulated species tree analysis 
was performed twice to check whether the runs converged and the ESS values were greater than 200. Bayes Factors ( $2 \ln \mathrm{Bf}$ ) were estimated from the MLE (combined from the two runs) to compare species group scenarios and select the most likely scenario (Kass \& Raftery, 1995): $2 \ln \mathrm{Bf}=0-2$ "not worth more than a bare mention"; $2 \ln \mathrm{Bf}=2-6$ "positive" support; $2 \ln \mathrm{Bf}=6-$ 10 "strong" support; and $2 \ln \mathrm{Bf}>10$ "decisive" support in distinguishing between competing hypotheses.

\subsection{Analysis of Morphological Convergence}

As the topological results of the molecular phylogenetic analysis data differed markedly from the previously published analysis based only on morphology (Ojanguren-Affilastro \& Ramírez, 2009), two suites of morphological characters associated with psammophily (the adaptation to sandy habitats) and with the complexity of the male genitalia, were investigated in more detail to determine whether they may be biased by concerted evolution.

Prendini (2001) defined three increasingly specialized ecomorphotypes among scorpions usually inhabiting loose gravelly or sandy substrata (semi-psammophilous, psammophilous, and ultrapsammophilous) according to the presence of particular morphological character states which confer improved locomotor or burrowing efficiency on these substrata and are hypothesized to be selectively advantageous, or adaptive. Eight character states (Appendix I) contributing to the ecomorphotypes defined by Prendini (2001), were identified among the species of Brachistosternus, on the basis of which an ensemble psammophily index, representing the sum of these character states present in each terminal or internal node, was calculated. The range of ecomorphotypes was scaled as follows: pelophilous (0-1); semi-psammophilous (2-4); psammophilous (5-7); ultrapsammophilous (psammophily index $=8-9$ ). Two species with different psammophilous character states may possess the same psammophily index, e.g., Brachistosternus pegnai Cekalovic, 1969 and Brachistosternus artigasi Cekalovic, 1974, both of which received a score of 3, but which possess character states 0,38 and 43 , and 38,40 and 43 , respectively.

In a similar manner, character states that contribute to the complexity of the male genitalia, or hemispermatophores, were identified (Appendix I), and an ensemble male genital complexity index was calculated. The ensemble indices for terminals were calculated directly from the morphological dataset and for the internal nodes from parsimony optimizations, using a node-driven approach described by Ramírez \& Michalik (2014). Ambiguous ancestral reconstructions were presented as the range of minimum and maximum values.

\section{Results}




\subsection{Phylogenetic reconstructions}

Nucleotide composition and site-specific information of the DNA data matrices used for phylogenetic reconstructions is outlined in Table 1. The results of parsimony, ML and MB were mostly congruent topologically, with minor differences limited to weakly supported groups (Fig. 1; supplementary figs. in Appendix J), except as discussed below. The tree obtained by simultaneous analysis of the mor+DNA+HVRs with BI (Fig. 1) is preferred. The tree obtained with implied weighting stabilized at values of the constant of concavity, $k$, ranging from 55 to 100. The tree recovered by this range of mild $k$ values was maximally congruent topologically with the preferred BI tree, and with the trees obtained by separate analyses of the morphological and molecular datasets (Appendix J), in agreement with the suggestion by Goloboff et al. (2008b) that mild concavities are preferable for DNA sequence data. Bootstrap percentages were calculated for $k=100$.

The monophyly of Brachistosternus, the nominal subgenus, and Ministernus were well supported (synapomorphies in Appendix K). Subgenus Ministernus comprised two monophyletic groups, one including B. andinus and Brachistosternus peruvuianus Toledo-Piza, 1974, the other including B. ferrugineus and B. simoneae. Both groups received high support.

Subgenus Brachistosternus comprised the remaining 37 species of the genus, grouped into four major clades. The clade placed sister to the rest, referred to as the "Pacific Coastal Desert Clade", comprised B. ehrenbergii, B. paposo, B. pegnai, and B. roigalsinai, which occur in the Pacific coastal desert from northern Chile to southern Ecuador. Brachistosternus ehrenbergii was placed sister to B. pegnai, and B. roiglasinai, sister to B. paposo.

The next clade of the nominal subgenus, referred to as the "Atacama Desert Clade", comprised four species from the lowlands of the Atacama Desert in northern Chile and southern Peru: B. mattonii; Brachistosternus ochoai Ojanguren-Affilastro, 2004; Brachistosternus turpuq Ochoa, 2002; and Brachistosternus sciosciae Ojanguren-Affilastro, 2002.

The remaining species of the genus were divided into two different clades. The first clade, referred to as the "Argentine Plains Clade", comprised all species from the plains of Argentina, i.e., Brachistosternus alienus Lönnberg, 1898, B. angustimanus, B. multidentatus, B. pentheri, and Brachistosternus telteca Ojanguren-Affilastro, 2000, and was well supported. Brachistosternus pentheri was consistently placed sister to the other species of this clade.

The second clade, referred to as the "Andean-Pacific Clade", comprised all species from high and intermediate altitudes of the Andes, as well as the remaining species from the plains of Chile and Peru excluded from the clades mentioned previously, and was also well supported. This clade comprised several smaller subclades, the first of which, recovered and well supported in the analyses, comprised five Chilean species, consistently arranged as follows: (Brachistosternus cepedai Ojanguren-Affilastro et al., 2007 (Brachistosternus negrei Cekalovic, 1975 (Brachistosternus chango Ojanguren-Affilastro et al., 2007 (Brachistosternus 
aconcagua Ojanguren-Affilastro \& Scioscia, 2007 Brachistosternus chilensis Kraepelin, 1911)))). The second subclade of the Andean-Pacific Clade, consistently recovered and well supported, comprised another three Chilean species, arranged as follows: (Brachistosternus coquimbo Ojanguren-Affilastro et al., 2007 (B. artigasi B. cekalovici)).

The remaining species of the Andean-Pacific Clade were consistently divided into two well supported groups. The first group included species from the Andes and the plains of Bolivia, Chile, and Peru, i.e., Brachistosternus barrigai Ojanguren-Affilastro \& Pizarro-Araya, 2014, Brachistosternus donosoi Cekalovic, 1974, Brachistosternus galianoae OjangurenAffilastro, 2002, B. kamanchaca, Brachistosternus ninapo Ochoa, 2004, Brachistosternus perettii Ojanguren-Affilastro \& Mattoni, 2006, Brachistosternus prendinii OjangurenAffilastro, 2003, and Brachistosternus quiscapata Ochoa \& Acosta, 2002. The second group was restricted to Andean species from high and intermediate altitudes in Argentina, Bolivia and Chile, i.e., B. intermedius, B. kovariki, B. montanus, B. piacentinii, B titicaca, B. weijemberghii, and B. zambrunoi

\subsection{Species Delimitation}

The results of the species delimitation analyses based on the GMYC and bGMYC methods are dubious. Whereas the single method GMYC and bGMYC "over-split" (i.e., identified more "species" than realistically present), the multiple method GMYC tended to "lump" together individuals belonging to different nominal species. The questionable results of the GMYC and bGMYC analyses (Appendix L) will not be considered further.

In contrast, the results of the BFD analyses were plausible. Based on the BFD analyses with PS and SS (Table 2), the inland and coastal dunes populations of B. cekalovici are conspecific, despite morphological differences, as are the populations of B. ehrenbergii, which formed at least two distinct clades; the geographically disjunct coastal and inland populations of $B$. multidentatus; and the geographically distant populations of B. paulae. However, the northwestern populations of $B$. angustimanus, the northern populations of B. montanus, B. roigalsinai and $B$. pentheri, and the southern populations of B. kamanchaca and B. weijenberghii are not conspecific with typical populations. The north-western populations of $B$. angustimanus, the northern populations of $B$. montanus and $B$. pentheri, and the southern populations of $B$. kamanchaca represent four undescribed species, whereas the southern populations of $B$. weijenberghii could correspond to B. borellii. Brachistosternus barrigai is conspecific with the typical, northern populations of B. kamanchaca.

According to the BFD analysis with SS, the northern populations of B. roigalsinai represent an undescribed species, distinct from B. paposo, whereas, according to the BFD 
analysis with PS, these populations are conspecific with B. paposo, which was placed within the northern clade of $B$. roigalsinai in most phylogenetic analyses

Both BFD analyses also suggested that B. intermedius comprises two species, but differed regarding which populations were assigned to each. According to the analyses with SS, Argentine populations are conspecific with $B$. intermedius, central Bolivian populations represent an undescribed species, and B. titicaca is a distinct species whereas, according to the analyses with PS, most northern Argentine populations and some central Bolivian populations, represent $B$. intermedius, some Argentine populations and some Bolivian populations represent an undescribed species, and some central Bolivian populations, presently regarded as $B$. intermedius, are conspecific with B. titicaca. Brachistosternus kovariki, B. piacentinii, and B. zambrunoi were recovered as distinct species in both analyses.

Based on the BFD analysis with SS, B. simoneae is conspecific with B. ferrugineus whereas, based on analysis with PS, B. simoneae is distinct from B. ferrugineus, the northern populations of which represent an undescribed species, distinct from the typical populations of central Argentina.

\subsection{Analysis of Morphological Convergence}

Optimization of the ensemble psammophily index revealed the ancestral ecomorphotype of Brachistosternus to be semi-psammophilous, consistent with occurrence of the basal species of the genus on loose (semi-consolidated) substrata in arid to semi-arid habitats. Further specialization for life on softer substrata, including sand dunes, occurred independently on four occasions, in the psammophilous species, B. sciosciae and B. zambrunoi, the ultrapsammophilous species, B. cepedai, and the sister-group comprising the ultra-psammophilous species, B. multidentatus and B. telteca (Fig. 2). Five species possessed only three or four of the six potential ecomorphological adaptations to life on sand, representing another four convergences, in B. galianoae, B. pentheri, and the monophyletic groups comprising B. artigasi and B. cekalovici, and B. ehrenbergii and B. pegnai.

Optimization of the ensemble hemispermatophore complexity index indicated that a marked increase in complexity (from 0 to at least 9) was ancestral for the genus (Fig. 2). The complexity of the hemispermatophore further increased on three independent occasions, among the species related to B. barrigai, B. ehrenbergi, and B. multidentatus, respectively, reaching its greatest complexity in $B$. ehrenbergii. A marked decrease in the complexity of the hemispermatophore also occurred on three independent occasions, among B. cepedai, B. sciosciae, and, to a lesser extent, B. paulae. 


\section{Discussion}

\subsection{Brachistosternus Phylogeny and Species Delimitation}

The monophyly of Brachistosternus was well supported in all analyses, as in previous phylogenetic studies (Prendini, 2000, 2003; Mattoni \& Prendini, 2007; Ojanguren-Affilastro \& Ramirez 2009). The genus is defined by 15 unambiguous synapomorphies. Two basal clades, corresponding to subgenera Brachistosternus and Ministernus, were also recovered, as previously (Ojanguren-Affilastro \& Ramirez, 2009). Both subgenera were also well supported, with 11 and 9 synapomorphies, respectively.

Subgenus Ministernus includes four described species, which consistently formed two monophyletic groups, one, including B. andinus and B. peruvianus, from the inter-Andean valleys of south-central Peru, and the other, including B. ferrugineus and B. simoneae, from semi-arid areas of central South America.

The species delimitation analyses were equivocal concerning the status of the different populations of $B$. ferrugineus, and the validity of $B$. simoneae. Accordingly, the known populations of $B$. ferrugineus are regarded as a single species, distinct from $B$. simoneae, pending further investigation.Subgenus Brachistosternus comprised 37 described species, as reported by Ojanguren-Affilastro \& Ramírez (2009). However, neither the "Plains" group of species nor the "Andean" group, reported by Ojanguren-Affilastro \& Ramírez (2009), were monophyletic in the analyses presented here, which instead recovered four well supported clades, the Pacific Coastal Desert Clade; the Atacama Desert Clade; the Argentine Plains Clade; and the Andean-Pacific Clade.

Although the Pacific Coastal Desert Clade was well-supported, the limits of some of its component species were ambiguous. All species delimitation tests consistently separated northern from southern populations of B. roigalsinai, despite the apparent absence of morphological differences among them. Further evaluation of the disparity between genetic and morphological variation in this species, sampling additional gene loci and populations from the extremes and intermediate parts of the distribution, and from offshore islands, is underway (Ojanguren-Affilastro et al., in prep.).

Three species of the Atacama Desert Clade, B. mattonii, B. ochoai and B. turpuq, are morphologically similar to species of the Argentine Plains clade, with which they formed a monophyletic group in the analyses of Ojanguren-Affilastro \& Ramírez (2009). According to the analyses presented here, however, these species diverged earlier than the Argentine species. The fourth species of the Atacama Desert Clade, B. sciosciae, was previously considered to be related to B. cepedai and B. paulae, two small species with similar external morphology, and simplification of the lobe region (internal spines, basal spines, spines in a row and basal triangle) of the hemispermatophore (Ojanguren-Affilastro \& Ramírez, 2009). According to most 
of the analyses presented here, these three species belong to different clades, and their hemispermatophores became simplified independently.

Brachistosternus paulae is the southernmost species of the genus, reaching the extreme south of the Patagonian plains at latitude $47^{\circ} \mathrm{S}$ (Ojanguren-Affilastro, 2003a). Although placed in the plains group of species, forming a clade with B. sciosciae and B. cepedai, in the morphological phylogeny of Ojanguren-Affilastro \& Ramírez (2009), its phylogenetic position differed among the various analyses presented here. The most biogeographically plausible position for this species is in the Argentine Plains Clade, as obtained by analyses of the molecular data with ML, BI, and parsimony with implied weighting and $k$ values between 55 and 100 .

The species delimitation analyses indicated that the northern populations of $B$. angustimanus represent a different species from the typical southern populations, a finding supported by morphological differences that were previously dismissed as intraspecific variation (Ojanguren-Affilastro \& Roig-Alsina, 2001). This discovery also suggests the possible importance of the Río Negro and Río Colorado rivers, in northern Patagonia, as an agent of vicariance in scorpions (Ojanguren-Affilastro et al., in prep.).

Brachistosternus multidentatus is among the few ultrapsammophilous species of the genus, known from only two populations inhabiting almost vegetationless dunes, about 1000 $\mathrm{km}$ apart. Several attempts to find additional populations of this species in the intervening area were unsuccessful. Despite the large distance between these apparently disjunct populations, specimens from both are morphologically similar, and were considered conspecific in the species delimitation analyses presented here. Presumably, the two populations were connected until recently, before grassland and steppe habitats developed in the intervening area. The possibility that additional populations occur in some suitable, yet inaccessible habitat in the arid regions of central Argentina, cannot be ruled out either.

Although northern populations of $B$. pentheri differ morphologically and in chromosome number (Rodríguez-Gil et al., 2009) from typical central and southern populations, neither difference was previously considered sufficient justification to recognize the northern populations as a different species. However, the species delimitation analyses presented here, taken together with previously noted differences in chromosome number and morphology, justify the recognition of a new species for these populations (Ojanguren-Affilastro et al., in prep.).

The Andean-Pacific Clade is the most complex and diverse group of Brachistosternus. The high diversity of this group, the minor differences between its component species, and the relatively new habitats, especially at high altitude, that they occupy, are consistent with a rapid and recent radiation.

Most species of the subclade comprising B. aconcagua, B. cepedai, B. chango, $B$. chilensis, and B. negrei, occur in plains, or at intermediate altitudes, in shrub steppes, grasslands 
and occasionally along sandy watercourses in forested habitats of central and southern Chile. However, B. cepedai inhabits arid dunes, almost $300 \mathrm{~km}$ north of the geographically closest species of the clade. This ultrapsammophilous species was previously considered to be closely related to B. sciosciae due to their similar external morphology and hemispermatophores (Ojanguren-Affilastro \& Ramírez, 2009). Based on the analyses presented here, however, the morphological character states that supported the previous sister-group hypothesis between $B$. cepedai and B. sciosciae, appear to be convergent. The two species are evidently not closely related and B. cepedai may be a northern relict of a once more widely distributed clade.

According to the species delimitation analyses presented here, $B$. barrigai is conspecific with the typical, northern populations of B. kamanchaca, with which it should be synonymized, whereas the southern populations of $B$. kamanchaca represent an undescribed species. These results, which conflict with the morphological diagnoses for these species (Ojanguren-Affilastro $\&$ Pizarro, 2014), require further evaluation before decisions are taken regarding the taxonomic status of B. barrigai and the southern populations of B. kamanchaca.

Also according to the species delimitation analyses, the southern populations of $B$. weijenberghii, which correspond to $B$. borellii, are not conspecific with the typical, northern populations, suggesting that $B$. borellii should be revalidated. Although slight morphological differences in pigmentation pattern and in the shape and length of the distal lamina of the hemispermatophore are evident between the northern and southern populations (OjangurenAffilastro, 2002b), this variation is bridged by populations from intermediate locations, suggesting clinal variation in a single species. Specimens from intermediate populations should therefore be included in future analyses, before decisions are taken regarding the taxonomic status of $B$. borellii.

The species delimitation analyses confirmed the earlier suggestion by OjangurenAffilastro (2003b) that the northern populations of B. montanus represent an undescribed species, to be described elsewhere (Ojanguren-Affilastro et al., in prep.), which differs from typical, southern populations in slight, but consistent morphological differences.

The identity of several populations of $B$. intermedius also remains equivocal. Various phylogenetic analyses recovered the different populations of $B$. intermedius as polyphyletic, comprising several smaller clades, and including other Andean species. The species delimitation analyses obtained with SS are considered more plausible, however, because they are independently supported by some morphological differences among the populations. On the basis of these analyses, the typical populations from northern Argentina and southern Bolivia are regarded as $B$. intermedius, whereas the populations from central Bolivia may represent an undescribed species to be confirmed with additional samples and analyses. Brachistosternus titicaca, restricted to the Titicaca basin of Bolivia and Peru, is considered distinct from $B$. intermedius. Brachistosternus kovariki, B. piacentinii, and B. zambrunoi are also considered valid species. 
Due to the nature of the multispecies coalescent, which provides more reliable results with larger sample sizes, the results obtained from the BFD analyses of species that were sparsely sampled, must be interpreted with caution. A wider range of molecular markers may also be desirable when thoroughly investigating species limits, where factors such as gene flow among populations should be considered (Carstens et al., 2013).

\subsection{Morphological Convergence}

All species of Brachistosternus scored at least 2 for the ensemble psammophily index, based on the presence of at least two ecomorphological adaptations to life on loose (semiconsolidated) substrata, i.e., laterally compressed telotarsi with setiform pro- and retroventral setae (Prendini, 2000). These adaptations are consistent with the semi-psammophilous ecomorphotype (Prendini, 2001), a precursor for the more stenotopic psammophilous and ultrapsammophilous ecomorphotypes of some species of Brachistosternus, which scored more than 2 for the ensemble psammophily index, based on the presence of additional adaptations for life on still softer, sandier substrata.

Brachistosternus ehrenbergii, B. pegnai, and B. pentheri each scored 3 for the ensemble psammophily index, although they inhabit the full range of substrata on which species of the genus may occur. Brachistosternus galianoae, known only from dark volcanic sands near the Sajama Volcano in the central Andes of Bolivia (Ojanguren-Affilastro 2002c), and characterized by dark infuscation rather than the pale, immaculate coloration typical of species that inhabit sandy substrata, also scored 4 for the index. The absence of pigmentation would presumably be deleterious on the dark sands inhabited by this species.

The morphological characters identified as psammophilous adaptations in Brachistosternus evolved in a similar manner among many distantly related scorpion taxa (Prendini, 2001). In contrast, characters concerning the complex lobe region of the male genitalia, or hemispermatophore of Brachistosternus have not been observed in other scorpion taxa, and may be unique to the genus (Ojanguren-Affilastro \& Ramírez, 2009). The ultimate, evolutionary reason for these structures is unknown, but they are probably involved in reproductive behaviour and may be sexually selected (Eberhard, 1996; Arnqvist, 1998). Species of subgenus Brachistosternus from the plains, that diverged basally, possess more complex internal structures of the hemispermatophore, e.g., well developed internal spines, basal spines and spines in a row, a large and chitinous basal triangle, and a large, usually clavate cylindrical apophysis, the plesiomorphic condition in the subgenus. On the other hand, Andean species, which appear to have radiated recently, possess less complex internal structures, e.g., internal spines are absent and the remaining spines weakly developed, the basal triangle and cylindrical apophysis are medium sized, and the apex of the apophysis is never thickened. It is unclear 
whether the decrease in complexity of the hemispermatophore is associated with life on softer, sandier substrata, or with some other aspect of the biology of these scorpions. These internal structures are absent or, if present, extremely reduced, in B. cepedai, B. paulae, and B. sciosciae, three small psammophilous species from the plains of Argentina and Chile, in which this simplification of the hemispermatophores appears to have evolved independently, but well developed in other psammophilous species, e.g., B. multidentatus.

Further investigation is necessary to better understand the factors promoting the evolution of these scorpions which are ubiquitous throughout the arid zone of southern South America. Exceptional adaptations for life on sandy substrata, and complex genitalia offer an excellent model system for such studies.

\section{Acknowledgements}

We thank Pablo Agusto, Fermín Alfaro-Kong, Juan Enrique Barriga-Tuñón, Ricardo Botero-Trujillo, Luís Compagnucci, Carolina Cuezzo, Cristian Grismado, Hernán Iuri, Matias Izquierdo, Paula Korob, Facundo Labarque, Juan José Martínez, José Mondaca, Luís Piacentini, and Jaime Pizarro-Araya, for assistance in the field; Yael Lubin, Ricardo Pinto-da-Rocha, Erich Volschenk and Humberto Yamaguti for donating material used in the study; Arturo Roig-Alsina (ARA), František Kovařík (FKPC), Sergio Roig-Juñent (IADIZA), Jaime Pizarro-Araya (LEULS), Mario Elgueta (MUSM), and Jorge Artigas (MZUC) for lending material from the collections in their care; and Ofelia Delgado-Hernandez, Patricia Rubi, and Tarang Sharma for generating DNA sequence data at the AMNH. This research was partially supported by a postgraduate grant and a postdoctoral grant from the Consejo Nacional de Investigaciones Científicas y Técnicas (CONICET), Argentina to AAOA, and by postdoctoral fellowships from the AMNH to CIM and JAO. Fieldwork was financially supported by CONICET grant PICT 2010-1764 to AAOA, by U.S. National Science Foundation grant EAR 0228699 and a grant from the Richard Lounsbery Foundation to LP, and by the AMNH. Part of the field equipment was donated to AAOA by Idea Wild (www.ideawild.org). Other funding came from CONICET grant PICT 2011-1007 to MJR. DNA sequencing was funded by the AMNH.

\section{References}

Agnarsson, I., Maddison, W. P., \& L. Avilés. 2007. The phylogeny of the social Anelosimus spiders (Araneae: Theridiidae) inferred from six molecular loci and morphology. Molecular Phylogenetics and Evolution. 43, 833-851.

Arnqvist, G. 1998. Comparative evidence for the evolution of genitalia by sexual selection. Nature. 393, 784-786.

Baele, G., Lemey, P., Bedford, T., Rambaut, A., Suchard, M. A., \& A. V. Alekseyenko. 2012. Improving the accuracy of demographic and molecular clock model comparison while 
accommodating phylogenetic uncertainty. Molecular Biology and Evolution. 29, 21572167.

Baele, G., Sibon Li, W. L. S., Drummond, A. J., Suchard, M. A., \& P. Lemey. 2013. Accurate model selection of relaxed molecular clocks in Bayesian phylogenetics. Molecular Biology and Evolution. 30, 239-243.

Baker, R. H., Yu, X., \& R. DeSalle. 1998. Assessing the relative contribution of molecular and morphological characters in simultaneous analysis trees. Molecular Phylogenetics and Evolution. 9, 427-436.

Brewer, M. S., Spruill, C. L., Rao, N. S., \& J. E. Bond. 2012. Phylogenetics of the millipede genus Brachycybe Wood, 1864 (Diplopoda: Platydesmida: Andrognathidae): Patterns of deep evolutionary history and recent speciation. Molecular Phylogenetics and Evolution. 64: $232-242$.

Brito, G. \& A. Borges. 2015. A checklist of the scorpions of Ecuador (Arachnida: Scorpiones), with notes on the distribution and medical significance of some species. Journal of Venomous Animals and Toxins including Tropical Diseases. 21, 23.

Carstens, B. C., Pelletier, T. A., Reid, N. M., \& J. D. Satler. 2013. How to fail at species delimitation. Molecular Ecology. 22, 4369-4383.

Castresana, J. 2000. Selection of conserved blocks from multiple alignments for their use in phylogenetic analysis. Molecular Biology and Evolution. 17, 540-552.

Ceccarelli, F. S., Sharkey, M. J., \& A. Zaldivar-Riveron. 2012. Species identification in the taxonomically neglected, highly diverse, Neotropical parasitoid wasp genus Notiospathius (Braconidae: Doryctinae) based on an integrative molecular and morphological approach. Molecular Phylogenetics and Evolution. 62, 485-495.

Crews, S. C., \& M. Hedin. 2006. Studies of morphological and molecular phylogenetic divergence in spiders (Araneae: Homalonychus) from the American southwest, including divergence along the Baja California Peninsula. Molecular Phylogenetics and Evolution. 38, 470-487.

Darriba, D., Taboada, G. L., Doallo, R., \& D. Posada. 2012. jModelTest 2: More models, new heuristics and parallel computing. Nature Methods. 9, 772.

Degnan, J. H. \& N. A. Rosenberg. 2009. Gene tree discordance, phylogenetic inference and the multispecies coalescent. Trends in Ecology and Evolution. 24, 332-340.

Drummond, A. J., Suchard, M. A., Xie, D., \& A. Rambaut. 2012. Bayesian phylogenetics with BEAUti and the BEAST 1.7. Molecular Biology and Evolution. 29, 1969-1973.

Eberhard, W. G. 1996. Female control: Sexual selection by cryptic female choice. Princeton University Press. 472 pp.

Ezard, T., Fujisawa, T., \& T. G. Barraclough. 2009. Splits: SPecies' LImits by Threshold Statistics. R package version 1.0-14/r31. <http://R-Forge.R-project.org/projects/ splits/>. 
Farias, I. P., Ortí, G., \& A. Meyer. 2000. Total evidence: Molecules, morphology, and the phylogenetics of cichlid Fishes. Journal of Experimental Zoology. 288, 76-92.

Felsenstein, J. 1985. Confidence limits on phylogenies: An approach using the bootstrap. Evolution. 39, 783-791.

Gajardo, R. 1993. La Vegetación Natural de Chile, Clasificación y Distribución Geográfica. Editorial Universitaria, Santiago, $165 \mathrm{pp}$.

Garzione C. N., Hoke, G. D., Libarkin, J. C., Withers, S., MacFadden, B., Eiler, J., Ghosh, P., \& A. Mulch. 2008. Rise of the Andes. Science. 320, 1304-1307.

Ghosh, P., Garzione, C. N., \& J. M. Eiler. 2006. Rapid uplift of the Altiplano revealed through 13C-18O bonds in paleosol carbonates. Science. 311, 511-516.

Goloboff, P. A. 2002. Techniques for analyzing large data sets. Pp. 70-79. In: R. DeSalle, G. Giribet, \& W. C. Wheeler. (Eds.) Methods and Tools in Biosciences and Medicine. Techniques in Molecular Systematics and Evolution. Birkhäuser Verlag AG, Basel.

Goloboff, P. A., Farris, J. S. \& K. C. Nixon. 2008a. TNT, a free program for phylogenetic analysis. Cladistics. 24, 774-786.

Goloboff, P. A., Carpenter, J. M., Arias, J. S., \& D. R. M. Esquivel. 2008b. Weighting against homoplasy improves phylogenetic analysis of morphological data sets. Cladistics. 24, 758 773.

González-Santillán, E. \& L. Prendini. 2014. Phylogeny of the North American vaejovid scorpion subfamily Syntropinae Kraepelin, 1905, based on morphology, mitochondrial and nuclear DNA. Cladistics. 31, 341-405.

Grummer, J. A., Bryson, Jr., R. W., \& T. W. Reeder. 2014. Species delimitation using Bayes factors: Simulations and application to the Scleropus scalaris species group (Squamata: Phrynosomatidae). Systematic Biology. 63, 119-133.

Hall, T. 1999. BioEdit: An important software for molecular biology. Nucleic Acids Symposium Series. 41, 95-98.

Hartley, A. J. 2003. Andean uplift and climate change. Journal of the Geological Society, London. 160, 7-10.

Hasegawa, M., Kishino, H., \& T. Yano. 1985. Dating of the human-ape splitting by a molecular clock of mitochondrial DNA. Journal of Molecular Evolution. 22, 160-174.

Hebert, P. D. N., Cywinska, A., Ball, S. L., \& J. R. de Waard. 2003. Biological identifications through DNA barcodes. Proceedings of the Royal Society, London, Ser. B. 270, 313-321.

Hedin, M., \& S. M. Thomas. 2010. Molecular systematics of eastern North American Phalangodidae (Arachnida: Opiliones: Laniatores), demonstrating convergent morphological evolution in caves. Molecular Phylogenetics and Evolution. 54: 107-121.

Heled, J., \& A. J. Drummond. 2010. Bayesian inference of species trees from multilocus data. Molecular Biology and Evolution. 27, 570-580. 
Kass, R. E., \& A. E. Raftery. 1995. Bayes factors. Journal of the American Statistical Association. 90, 773-795.

Kovařík, F., \& A. A. Ojanguren-Affilastro. 2013. Illustrated catalog of scorpions. Part II. Bothriuridae; Chaerilidae; Buthidae I., genera Compsobuthus, Hottentotta, Isometrus, Lychas, and Sassanidotus. Jakub Rolčík Publisher, Czech Republic. 400 pp.

Lartillot, N., \& H. Philippe. 2006. Computing Bayes factors using thermodynamic integration. Systematic Biology. 55, 195-207.

Lanfear, R., Kokko, H., \& A. Eyre-Walker. 2014. Population size and the rate of evolution. Trends in Ecology and Evolution. 29, 33-41.

Lopardo, L., Giribet, G., \& G. Hormiga. 2011. Morphology to the rescue: Molecular data and the signal of morphological characters in combined phylogenetic analyses - a case study from mysmenid spiders (Araneae, Mysmenidae), with comments on the evolution of web architecture. Cladistics. 27, 278-330.

Lourenço, W. R. 2000. Confirmation de la présence de genere Brachistosternus Pocock (Scorpiones, Bothriuridae) au Brésil et description d'une espèce nouvelle. Revue Arachnologique. 13, 93-100.

Lowe, G., \& V. Fet. 2000. Family Bothriuridae Simon, 1880. Pp. 17-53. In V. Fet, W. D. Sissom, G. Lowe, \& M. E. Braunwalder. Catalog of the Scorpions of the World (17581998). The New York Entomological Society, New York.

Lutzoni, F., Wagner, P., Reeb, V., \& S. Zoller. 2000. Integrating ambiguously aligned regions of DNA sequences in phylogenetic analyses without violating positional homology. Systematic Biology. 49, 628-651.

Mattoni, C. I., \& L. Prendini. 2007. Phylogeny and biogeography of the family Bothriuridae (Scorpiones). Darwiniana. 45(supl.), 96-98.

Miller, M.A., Pfeiffer, W., \& T. Schwartz. 2010. Creating the CIPRES Science Gateway for inference of large phylogenetic trees in Proceedings of the Gateway Computing Environments Workshop (GCE), 14 Nov. 2010, New Orleans, LA, pp. 1-8.

Miralles, A., \& M. Vences. 2013. New metrics for comparison of taxonomies reveal striking discrepancies among species delimitation methods in Madascincus lizards. PLoS One. 8, e68242.

Monaghan, M. T., Wild, R., Elliot, M., Fujisawa, T., Balke, M., Inward, D. J., Lees, D. C., Ranaivosolo, R., Eggleton, P., Barraclough, T. G., \& A. P. Vogler. 2009. Accelerated species inventory on Madagascar using coalescent-based models of species delineation. Systematic Biology. 58, 298-311.

Mott, T., \& D. R. Vieites. 2009. Molecular phylogenetics reveals extreme morphological homoplasy in Brazilian worm lizards challenging current taxonomy. Molecular Phylogenetics and Evolution. 51, 190-200. 
Nime, M. F., Casanoves, F., Vrech, D., \& C. I. Mattoni. 2013. Relationship between environmental variables and the surface activity of the scorpions in a reserve of arid Chaco, Argentina. Invertebrate Biology. 132, 145-155.

Nime, M. F., Casanoves, F., \& C. I. Mattoni. 2014. Surface activity, sex ratio and diversity of scorpions in two different habitats in an arid Chaco reserve, Argentina. Journal of Insect Conservation. 18, 373-384.

Ochoa, J. A. 2004. Filogenia del género Orobothriurus y descripción de un nuevo género de Bothriuridae (Scorpiones). Revista Ibérica de Aracnología. 9, 43-73.

Ochoa, J. A. \& L. E. Acosta. 2002. Two new Andean species of Brachistosternus Pocock (Scorpiones: Bothriuridae). Euscorpius. 2, 1-13.

Ochoa, J. A. \& A. A. Ojanguren-Affilastro. 2007. Systematics and distribution of Brachistosternus (Brachistosternus) ehrenbergii (Gervais, 1841), with the first record of stridulation in the genus Brachistosternus. Studies on Neotropical Fauna and Environment. $42,61-69$.

Ojanguren-Affilastro, A. A. 2002a. Aportes al conocimiento del género Brachistosternus en Chile, con la descripción de dos nuevas especies (Scorpiones, Bothriuridae). Boletín de la Sociedad Biológica de Concepción. 73, 37-46.

Ojanguren-Affilastro, A. A. 2002b. Sistemática y distribución de Brachistosternus weyenberghi Thorell. Revista del Museo Argentino de Ciencias Naturales. 4, 203-208.

Ojanguren-Affilastro, A. A. 2002c. Brachistosternus galianoae (Scorpiones, Bothriuridae) una nueva especie de Bolivia. Revista del Museo Argentino de Ciencias Naturales. 4, 105-109.

Ojanguren-Affilastro, A. A. 2003a. The genus Brachistosternus in Argentina, with the description of a new species from Patagonia (Scorpiones, Bothriuridae). Journal of Arachnology. 31, 317-331

Ojanguren-Affilastro, A. A. 2003b. Nuevos aportes al conocimiento de las especies andinas de Brachistosternus (Leptosternus), con la descripción de tres nuevas especies. Revista Ibérica de Aracnología 8, 23-36.

Ojanguren-Affilastro, A. A. 2004a. Sistemática y distribución de Brachistosternus (Leptosternus) intermedius Lönnberg (Scorpiones, Bothriuridae). Physis, Buenos Aires, Sec. C. 59, 29-35.

Ojanguren-Affilastro, A. A., Mattoni, C. \& L. Prendini. 2007. The genus Brachistosternus in Chile (Scorpiones: Bothriuridae), with the description of two new species. American Museum Novitates. 3564, 1-44.

Ojanguren-Affilastro, A. A. \& A. Roig-Alsina. 2001. Brachistosternus angustimanus, una nueva especie del norte de la Patagonia, Argentina (Scorpiones, Bothriuridae). Physis, Buenos Aires, Sec. C. 58, 15-22.

Ojanguren-Affilastro, A. A. \& M. J. Ramírez. 2009. Phylogenetic analysis of the scorpion genus Brachistosternus (Arachnida, Scorpiones, Bothriuridae). Zoologica Scripta. 38, 183-198. 
Ojanguren-Affilastro, A. A. \& J. Pizarro-Araya. 2014. Two new scorpion species from Paposo, in the coastal desert of Taltal, Chile (Scorpiones, Bothriuridae, Brachistosternus). Zootaxa. $3785,400-418$.

Pons, J., Barraclough, T. G., Gomez-Zurita, J., Cardoso, A., Duran, D. P., Hazell, S., Kamoun, S., Sumlin, W. D., \& A. P. Vogler. 2006. Sequence-based species delimitation for the DNA taxonomy of undescribed insects. Systematic Biology. 55, 595-609.

Prendini, L. 2000. Phylogeny and classification of the superfamily Scorpionoidea Latreille 1802 (Chelicerata, Scorpiones): An exemplar approach. Cladistics. 16, 1-78.

Prendini, L. 2001. Substratum specialization and speciation in southern African scorpions: The Effect Hypothesis revisited. Pp. 113-138. In: V. Fet \& P. A. Selden. (Eds.) Scorpions 2001: In Memoriam Gary A. Polis. British Arachnological Society, Burnham Beeches, UK.

Prendini, L., Hanner, R., \& R. DeSalle. 2002. Obtaining, storing and archiving specimens and tissue samples for use in molecular studies. Pp. 176-248. In: R. DeSalle, G. Giribet, \& W. C. Wheeler. (Eds.) Methods and Tools in Biosciences and Medicine. Techniques in Molecular Evolution and Systematics. Birkhäuser Verlag AG, Basel.

Prendini, L. 2003. A new genus and species of bothriurid scorpion from the Brandberg Massif, Namibia, with a reanalysis of bothriurid phylogeny and a discussion of the phylogenetic position of Lisposoma Lawrence. Systematic Entomology. 28, 149-172.

Prendini, L., Crowe, T. M., \& W. C. Wheeler. 2003. Systematics and biogeography of the family Scorpionidae Latreille, with a discussion of phylogenetic methods. Invertebrate Systematics. 17, 185-259.

Prendini, L., Weygoldt, P., \& W. C. Wheeler. 2005. Systematics of the Damon variegatus group of African whip spiders (Chelicerata: Amblypygi): Evidence from behaviour, morphology and DNA. Organisms, Diversity and Evolution. 5, 203-236.

Quicke, D. L. J., \& R. Belshaw. 1999. Incongruence between morphological data sets: An example from the evolution of endoparasitism among parasitic wasps (Hymenoptera: Braconidae). Systematic Biology. 48, 436-454.

Rambaut, A., \& A. J. Drummond. 2007. Tracer v1.5. University of Edinburgh, Edinburgh, U.K. $<$ http://beast.bio.ed.ac.uk/Tracer>.

Ramírez, M. J., \& P. Michalik. 2014. Calculating structural complexity in phylogenies using ancestral ontologies. Cladistics. 30, 635-649.

Reid, N. M., \& B. C. Carstens. 2012. Phylogenetic estimation error can decrease the accuracy of species delimitation: A Bayesian implementation of the general mixed Yule-coalescent model. BMC Evolutionary Biology. 12, 196.

Rodriguez-Gil, S., Ojanguren-Affilastro A. A., Barral, L., Scioscia, C. L., \& L. Mola. 2009. Cytogenetics of three species of Brachistosternus Pocock from Argentina (Scorpiones, Bothriuridae). Journal of Arachnology. 37, 331-337. 
Roig-Alsina, A. H., \& E. A. Maury. 1981. Consideraciones sistemáticas y ecológicas sobre Brachistosternus (Leptosternus) borellii Kraepelin, 1911 (Scorpiones, Bothriuridae). Physis, Buenos Aires, Sec. C. 39, 1-9.

Roig-Alsina, A. H., \& E. A. Maury. 1984. Sistemática y distribución geográfica de Brachistosternus (L.) pentheri Mello-Leitão, 1931 (Scorpiones, Bothriuridae). Physis, Buenos Aires, Sec. C. 42: 17-21.

Ronquist, F., Klopfstein, S., Vilhelmsen, L., Schulmeister, S., Murray, D. L., \& A. P. Rasnitsyn. 2012. A total-evidence approach to dating with fossils, applied to the early radiation of the Hymenoptera. Systematic Biology. 61, 973-999.

Sanderson, M. J. 2002. Estimating absolute rates of molecular evolution and divergence times: A penalized likelihood approach. Molecular Biology and Evolution. 19, 101-109.

Sanderson, M. J. 2003. r8s: Inferring absolute rates of molecular evolution and divergence times in the absence of a molecular clock. Bioinformatics. 19, 301-302.

Santibáñez-Lopez, C. E., Francke, O. F., \& L. Prendini. 2014. Phylogeny of the North American scorpion genus Diplocentrus Peters, 1861 (Scorpiones: Diplocentridae) based on morphology, nuclear and mitochondrial DNA. Arthropod Systematics and Phylogeny. 72, 257-279.

Schmidt, H. A., Strimmer, K., Vingron, M., \& A. von Haeseler. 2002. Tree-Puzzle: Maximum likelihood phylogenetic analysis using quartets and parallel computing. Bioinformatics. 18, 502-504.

Schwarz, G. 1978. Estimating the dimension of a model. Annals of Statistics. 6, 461-464.

Stamatakis, A. 2006. RAxML-VI-HPC: Maximum likelihood-based phylogenetic analyses with thousands of taxa and mixed models. Bioinformatics. 22, 2688-2690.

Stamatakis, A., Auch, A. F., Meier-Kolthoff, J., \& M. Göker. 2007. AxPcoords and parallel AxParafit: Statistical co-phylogenetic analyses on thousands of taxa. BMC Bioinformatics. 8, 405. doi: 10.1186/1471-2105-8-405.

Talal, S., Tesler, I., Sivan, J., Ben-Shlomo, R., Tahir, H. M., Prendini, L., Snir, S., \& E. Gefen. 2015. Scorpion speciation in the Holy Land: Multilocus phylogeography corroborates diagnostic differences in morphology and burrowing behavior among Scorpio subspecies and justifies recognition as phylogenetic, ecological and biological species. Molecular Phylogenetics and Evolution 91, 226-237.

Wagner, G. P. 2001. The Character Concept in Evolutionary Biology. Academic Press, San Diego.

Xie, W., Lewis, P. O., Fan, Y., Kuo, L., \& M. H. Chen. 2011. Improving marginal likelihood estimation for Bayesian phylogenetic model selection. Systematic Biology. 60, 150-160.

Yamaguti, U. H., \& R. Pinto-da-Rocha. 2006. Biological aspects of Thestylus aurantiurus in the Parque Estadual da Cantareira, Brazil. Journal of Arachnology. 34, 214-220. 
Vachon, M. 1973 (1974). Étude des caractères utilisés pour classer les familles et les genres de scorpions (Arachnides). 1. La trichobothriotaxie en arachnologie. Sigles trichobothriaux et types de trichobothriotaxie chez les scorpions. Bulletin du Muséum National d'Histoire Naturelle, Ser. 3, 140, 857-958. 


\section{Figure captions}

Fig. 1. Preferred phylogeny of the South American bothriurid scorpion genus Brachistosternus Pocock, 1893 obtained by Bayesian Inference of 4142 aligned nucleotides from two nuclear (18S rDNA, 28S rDNA) and three mitochondrial (12S rDNA, 16S rDNA, Cytochrome c Oxidase Subunit I) gene loci (Appendix A), and 116 morphological characters (Appendices C, D). Support values for Bayesian posterior probabilities with DNA+morphology (PP), Bayesian posterior probabilities with DNA only (PP-DNA), parsimony with implied weights (bootstrap; Piw-B, concavity constant, $k$, from 55 to 100), parsimony with equal weights (bootstrap; PewB) and maximum likelihood (bootstrap; ML-B) shown at nodes, symbols explained in legend. Brachistosternus paulae Ojanguren-Affilastro, 2003, considered most closely related to the Argentine Plains Clade, is colored as different from the Andean-Pacific Clade (see discussion for details).

Fig. 2. Morphological convergence revealed by character optimization on the preferred phylogeny of the South American bothriurid scorpion genus Brachistosternus Pocock, 1893 (Figure 1). A. Psammophily optimized as an ensemble index, indicating that extreme specialization evolved on at least four independent occasions. B. Complexity of male hemisperpatophore optimized as an ensemble index, indicating that the lobe regions increased in complexity on three independent occasions, and decreased in complexity on another three independent occasions. 
Table 1

\begin{tabular}{lllllll}
\hline Marker & Haplo. & Unalign. & Align. & VP & PI & GC \\
\hline $18 \mathrm{~S}$ & 6 & 1761 & 1761 & 8 & 7 & 51.1 \\
$28 \mathrm{~S}$ & 36 & $513-517$ & 517 & 26 & 15 & 60 \\
$12 \mathrm{~S}$ & 90 & $330-339$ & 324 & 139 & 104 & 21.8 \\
$16 \mathrm{~S}$ & 94 & $481-486$ & 463 & 143 & 117 & 27.2 \\
COI & 102 & 1078 & 1078 & 143 & 122 & 35.7 \\
COI codon pos 1 & 28 & 359 & 359 & 22 & 13 & 47.6 \\
COI codon pos 2 & 12 & 359 & 359 & 7 & 6 & 41.4 \\
COI codon pos 3 & 102 & 359 & 359 & 114 & 103 & 18.2 \\
\hline
\end{tabular}

Nucleotide diversity and composition of aligned nuclear 18S rDNA (18S) and 28S rDNA (28S), and mitochondrial 12S rDNA (12S), 16S rDNA (16S) and Cytochrome c Subunit I (COI) sequences used for phylogenetic analysis of the South American bothriurid scorpion genus Brachistosternus Pocock, 1893: number of haplotypes; unaligned base-pairs; aligned base-pairs, excluding five hypervariable regions which were recoded as presence/absence (Appendix F); number of variable positions (VP); number of parsimony-informative (PI) positions; and percentage GC content (GC). Numbers for COI represent total, first, second and third codon positions. 
Table 2

\begin{tabular}{|c|c|c|c|c|c|c|c|}
\hline & HO & HA1 & HA2 & HA3 & HA4 & HA5 & HA6 \\
\hline \multicolumn{8}{|c|}{ Brachistosternus angustimanus and B. pentheri } \\
\hline MLE by & -11171.32 & -11172.26 & -11177.14 & & & & \\
\hline PS & $(* * *)$ & $(1.88)$ & $(11.64)$ & & & & \\
\hline$(2 \ln \mathrm{BF})$ & & & & & & & \\
\hline MLE by & -11098.41 & -11088.11 & -11084.38 & & & & \\
\hline SS & $(28.06)$ & $(7.46)$ & $(* * *)$ & & & & \\
\hline$(2 \ln \mathrm{BF})$ & & & & & & & \\
\hline \multicolumn{8}{|c|}{ Brachistosternus cekalovici } \\
\hline MLE by & -5324.79 & -5339.23 & -5329.13 & -5333.91 & & & \\
\hline PS & $(* * *)$ & $(28.88)$ & $(8.68)$ & $(18.24)$ & & & \\
\hline$(2 \ln \mathrm{BF})$ & & & & & & & \\
\hline MLE by & -5222.63 & -5287.32 & -5251.57 & -5299.32 & & & \\
\hline & & (129.38) & $(57.88)$ & (153.38) & & & \\
\hline$(2 \ln \mathrm{BF})$ & & & & & & & \\
\hline \multicolumn{8}{|c|}{ Brachistosternus ehrenbergii } \\
\hline MLE by & -8496.49 & -8506.67 & & & & & \\
\hline PS & $(* * *)$ & $(20.36)$ & & & & & \\
\hline$(2 \ln \mathrm{BF})$ & & & & & & & \\
\hline MLE by & -8416.32 & -8481.97 & & & & & \\
\hline SS & $(* * *)$ & $(131.3)$ & & & & & \\
\hline$(2 \ln \mathrm{BF})$ & & & & & & & \\
\hline \multicolumn{8}{|c|}{ Brachistosternus ferrugineus } \\
\hline MLE by & -7554.59 & -7540.95 & -7537.22 & & & & \\
\hline PS & $(34.74)$ & $(7.46)$ & $(* * *)$ & & & & \\
\hline$(2 \ln \mathrm{BF})$ & & & & & & & \\
\hline MLE by & -7538.56 & -7503.07 & -7507.75 & & & & \\
\hline $\mathrm{SS}$ & $(61.62)$ & $(* * *)$ & $(9.36)$ & & & & \\
\hline$(2 \ln \mathrm{BF})$ & & & & & & & \\
\hline \multicolumn{8}{|c|}{ Brachistosternus intermedius } \\
\hline MLE by & -7959.04 & -7941.81 & -7933.78 & -7937.1 & -7932.58 & -7935.26 & -7938.45 \\
\hline PS & $(52.92)$ & $(18.46)$ & $(2.4)$ & $(9.04)$ & $(* * *)$ & $(5.36)$ & $(11.74)$ \\
\hline$(2 \ln \mathrm{BF})$ & & & & & & & \\
\hline MLE by & -7953.88 & -7924.06 & -7894.94 & -7902.14 & -7909.02 & -7899.45 & -7893.26 \\
\hline & $(121.24)$ & $(61.6)$ & $(3.36)$ & $(17.76)$ & $(31.52)$ & $(12.38)$ & $(* * *)$ \\
\hline$(2 \ln \mathrm{BF})$ & & & & & & & \\
\hline \multicolumn{8}{|c|}{ Brachistosternus kamanchaca } \\
\hline MLE by & -8581.32 & -8570.3 & -8581.24 & & & & \\
\hline PS & $(22.04)$ & $(* * *)$ & $(21.88)$ & & & & \\
\hline$(2 \ln \mathrm{BF})$ & & & & & & & \\
\hline MLE by & -8559.07 & -8541.63 & -8577.25 & & & & \\
\hline & $(34.88)$ & $(* * *)$ & $(71.24)$ & & & & \\
\hline$(2 \ln \mathrm{BF})$ & & & & & & & \\
\hline \multicolumn{8}{|c|}{ Brachistosternus montanus and $B$. weijenberghii } \\
\hline MLE by & -8333.24 & -8346.25 & -8320.14 & & & & \\
\hline PS & $(26.2)$ & $(52.22)$ & $(* * *)$ & & & & \\
\hline$(2 \ln \mathrm{BF})$ & & & & & & & \\
\hline MLE by & -8321.91 & -8332.21 & -8302.85 & & & & \\
\hline & $(38.12)$ & $(58.72)$ & $(* * *)$ & & & & \\
\hline$(2 \ln \mathrm{BF})$ & & & & & & & \\
\hline \multicolumn{8}{|c|}{ Brachistosternus multidentatus } \\
\hline MLE by & -3840.44 & -3847.27 & & & & & \\
\hline & $(* * *)$ & $(13.66)$ & & & & & \\
\hline$(2 \ln \mathrm{BF})$ & & & & & & & \\
\hline MLE by & -3832.35 & -3845.37 & & & & & \\
\hline SS & $(* * *)$ & $(26.04)$ & & & & & \\
\hline$(2 \ln \mathrm{BF})$ & & & & & & & \\
\hline Brachisto & ulae & & & & & & \\
\hline
\end{tabular}




\begin{tabular}{llllll} 
MLE by & $\mathbf{- 8 4 3 7 . 7 8}$ & -8466.07 & -8465.19 & -8446.87 & -8457.27 \\
PS & $(* * *)$ & $(56.58)$ & $(54.82)$ & $(18.18)$ & $(38.98)$ \\
$\begin{array}{l}(2 \ln \mathrm{BF}) \\
\text { MLE by }\end{array}$ & $\mathbf{- 8 4 0 8 . 0 8}$ & -8453.81 & -8455.24 & -8421.77 & -8434.92 \\
SS & $(* * *)$ & $(91.46)$ & $(94.32)$ & $(27.38)$ & $(53.68)$ \\
$\begin{array}{l}(2 \ln \mathrm{BF}) \\
\text { Brachistosternus roigalsinai }\end{array}$ & & \\
MLE by & -8194.53 & -8197.56 & $\mathbf{- 8 1 8 5 . 1}$ & -8185.28 & \\
$\begin{array}{l}\text { PS } \\
(2 \ln \mathrm{BF})\end{array}$ & $(18.86)$ & $(24.92)$ & $\mathbf{( * * * )}$ & $(0.36)$ \\
$\begin{array}{l}\text { MLE by } \\
\text { SS }\end{array}$ & -8183.75 & -8180.71 & -8178.98 & $\mathbf{- 8 1 6 9}$ & \\
$(2 \ln \mathrm{BF})$ & $(29.5)$ & $(23.42)$ & $(19.96)$ & $\mathbf{( * * * )}$ & \\
\hline
\end{tabular}

Marginal likelihood estimation (MLE) values recovered by path-sampling (PS) or stepping-stone sampling (SS) for null (H0) and alternative (HA1-A6) hypotheses with Bayes Factor Species Delimitation of selected samples of the South American bothriurid scorpion genus Brachistosternus Pocock, 1893. Bayes Factors (2lnBf) were estimated from the MLE to compare species group scenarios and select the most likely scenario. Preferred hypotheses in boldface. Lists of individuals and putative species groupings in Appendix $\mathrm{H}$. 

B. kovariki (4288)

B. montanus (northern) (5190) B. montanus (northern) (5833)

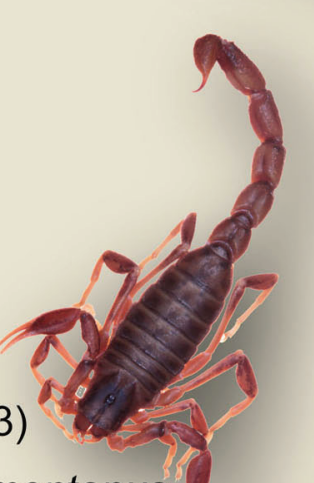

0.0.0. B. weijenberghii (4299) B. we.jenberghii (4300) B. weijenberghii (4301)

0.0.0. B. kamanchaca (2413)

B. kamanchaca (2414) B. kamanchaca (2422)

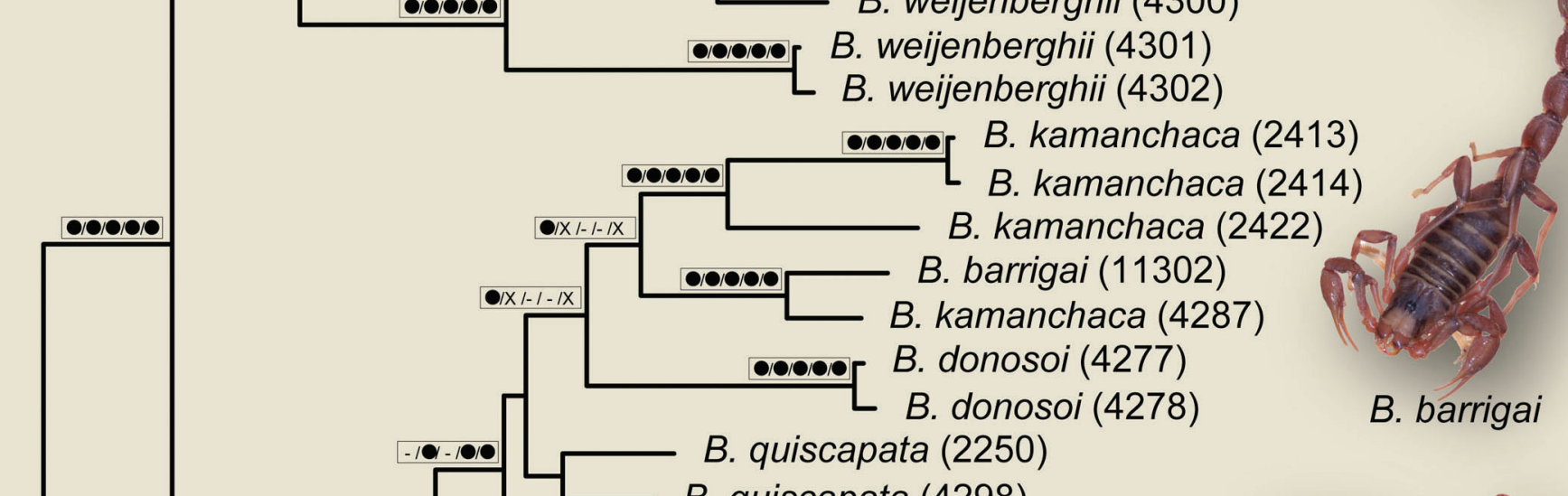
B. quiscapata (2250) B. prendinii $(4297)$

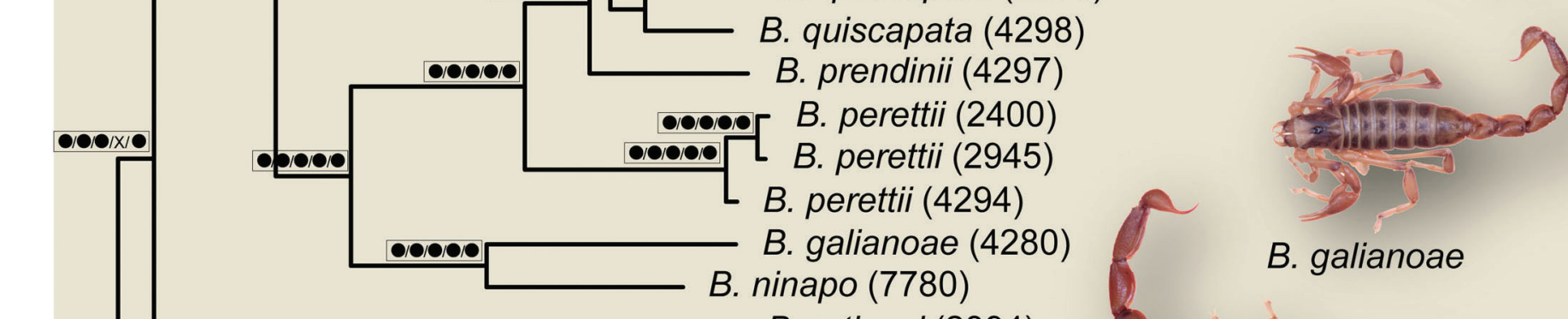

Node support legend PP/PP-DNA/Piw-B/Pew-B/ML-B - $\mathrm{P}-\mathrm{B} / \mathrm{ML}-\mathrm{B}>75 \%, \mathrm{PP}>0.95$

$0.9<P P<0.95$

\section{$X$ Clade not recovered} B. artigasi (2394)
B. artigasi (5832) B. cekalovici (5842)
B. cekalovici (2387)
B. cekalovici (2388) B. cekalovici (5838)

B. cekalovici (2406)

B. coquimbo (5840)

B. aconcagua (5189)

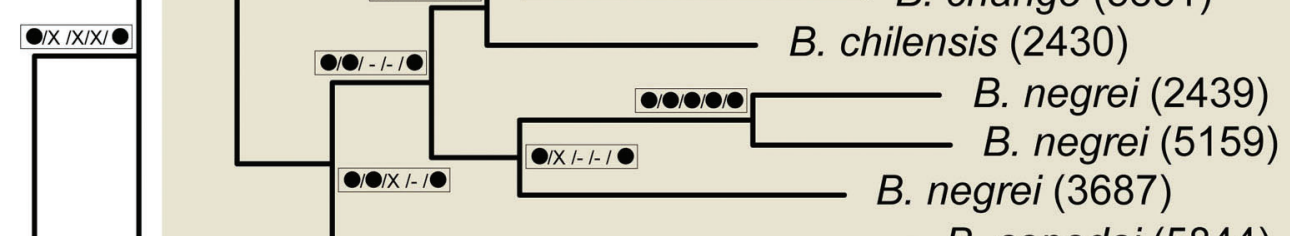

B. paulae (4292)

Argentine B. paulae (4291) (4293) $\begin{array}{ll}\text { Argentine } & \text { Plains Clade }\end{array}$ 8442
(56)
57)
83)

B. coquimbo
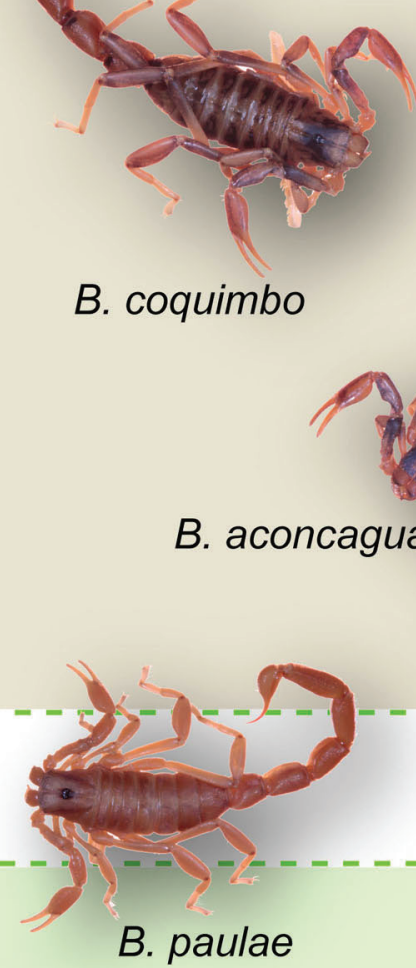

B. angustimanus (2255)

B. angustimanus (2254)

B. angustimanus (5665)

.0.0.0. alienus (2256)

B. alienus (2251)

B. pentheri (2252) B. pentheri (8482) B. pentheri $(8482)$

B. angustimanus

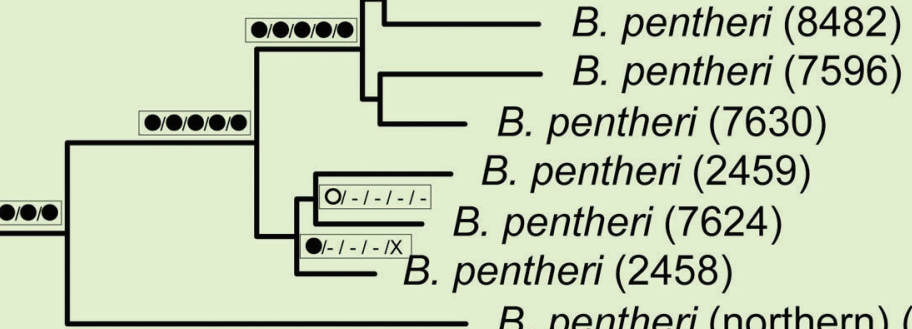

Atacama Desert
Clade

Clade

0.0. B. sciosciae (2412)

B. sciosciae (2423)

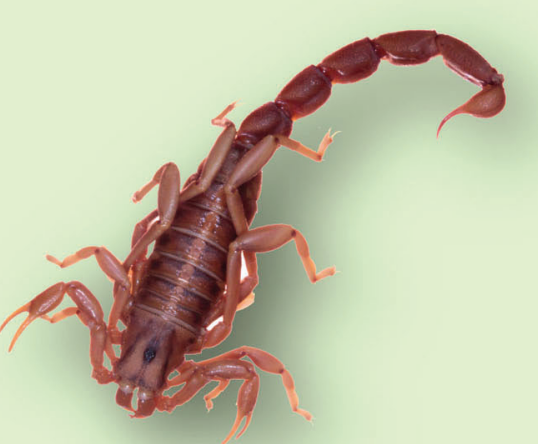

\section{S} B. ehrenbergii (8344)

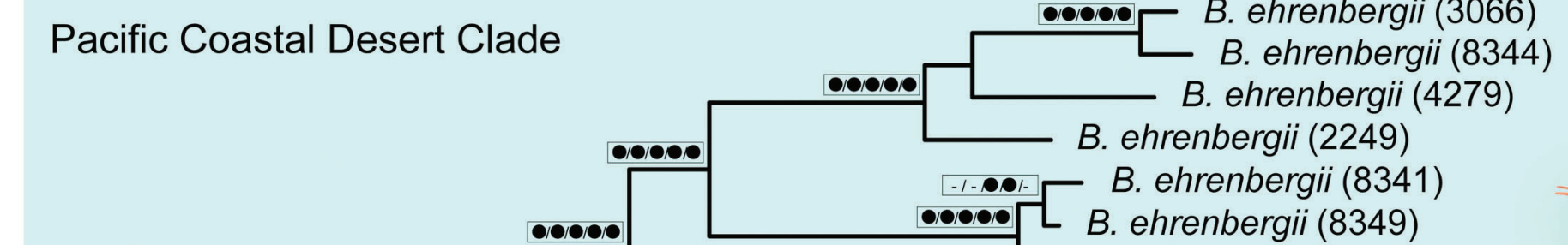

B. ochoai

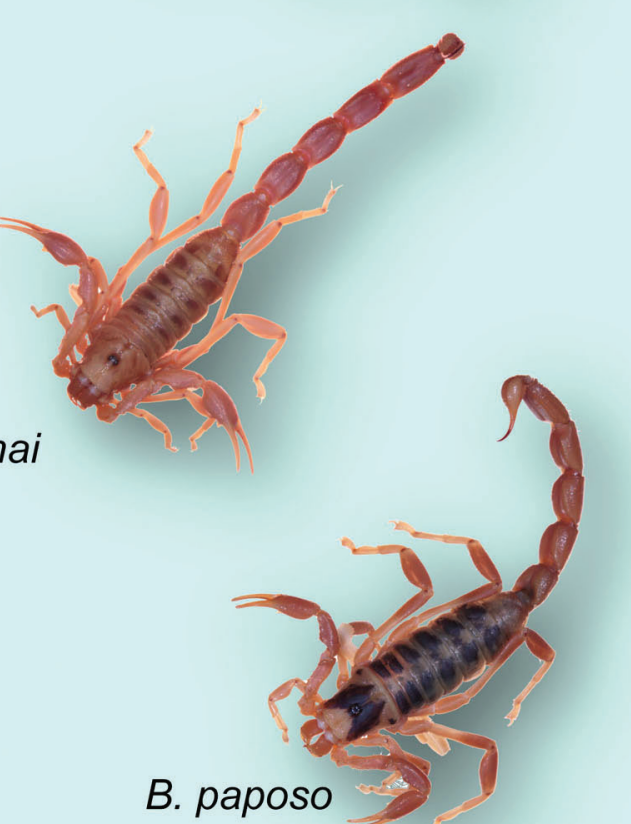

B. paposo (11301)

B. roigalsinai (2416)

B. paposo

\section{- 6 B pegnai (6264B)}

B. roigalsinai (5837)

\%.cos L B roigalsinai (7623)

...... [ B. roigalsinai (7627)

B...0. roigalsinai (2407)

B. pegnai

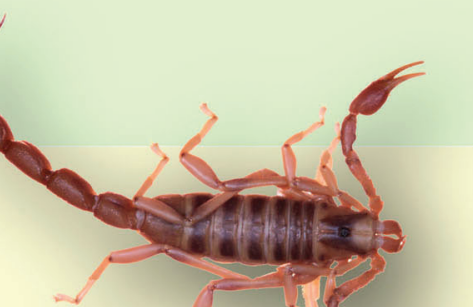


